\title{
Research on the relationship between vegetation and soil resource patterns on lands abandoned at different times
}

\author{
Jian Hou, Bojie Fu* \\ State Key Laboratory of Urban and Regional Ecology, Research Center for Eco-Environmental Sciences, Chinese Academy of Sciences, P. O. Box 2871, Beijing 100085, PR China
}

\section{A R T I C L E I N F O}

\section{Article history:}

Received 19 June 2013

Received in revised form 4 November 2013

Accepted 12 November 2013

\section{Keywords:}

Vegetation

Soil resource

Resource islands

Resource pattern

Geo-statics analysis

Point pattern analysis

\begin{abstract}
A B S T R A C T
Many studies on the effect of vegetation on soil resources have compared the patterns of soil resources in different land environments. Few studies have compared the spatial pattern of soil resources in different secondary succession stages. Although various studies have evaluated the heterogeneous soil resources patterns caused by vegetation, few have provided high-resolution analyses of heterogeneous soil resource patterns on a fine scale, with the exception of trees and shrubs. This study has been performed on four abandoned farms (abandoned for 4, 12, 22, and 50 years) to evaluate the dynamic effect of vegetation on soil resource patterns at the scale of herbaceous plants. It was found that dominant species in a vegetation family at a given succession stage will play a primary role in the formation of resource islands. Resource islands developed during vegetative succession and subsequently change the patterns of soil resources. There are different soil resource patch sizes and soil parameter patterns on farms abandoned for different periods. A method was developed for this study called the Integration of Geostatistics, Point pattern analysis and Spatial comparison to provide an effective method to research the effect of vegetation on soil resource patterns at a fine scale.
\end{abstract}

(c) 2013 Elsevier B.V. All rights reserved.

\section{Introduction}

Recently, there has been a great deal of research concerning the heterogeneous soil resource patterns that occur following the formation of "resource islands" that often appear in arid and semi-arid ecosystems around the world (Puigdefabregas, 2005; Segoli et al., 2008). Resource islands are defined as vegetation patches that accumulate nutrients and water from the environment and thus become increasingly nutrient rich, while the space between resource islands become increasingly nutrient poor (Reynolds et al., 1999).

There are several significant aspects to this research topic. First, the short- and long-term feedback relationship between vegetation and soil resources in arid and semi-arid ecosystems requires further investigation. This area of investigation couples plant ecology and soil science (Sauer et al., 2006). It is also important to understand the formation of resource islands and to identify their ecological function at the population, community, and ecosystem levels (Robertson et al., 1993). Second, a research on this topic can provide useful information to land managers about the scale of soil nutrient patterns. This information is useful for managers to clearly understand ground conditions and effectively manage their land. Third, a proper understanding of this topic is necessary to avoid the spatial autocorrelation of soil elements when performing field experiments (Rodríguez et al., 2009b).

The factors and processes that determine soil resource patterns in arid or semi-arid ecosystems have been discussed in research reports

\footnotetext{
* Corresponding author. Tel./fax: +8610 62923557.

E-mail address: bfu@rcees.ac.cn (B. Fu).
}

over the past two decades (Guo et al., 2002; Okin et al., 2008; Robertson et al., 1997). Soil resources are primarily controlled by pedogenic factors, such as climate, topography and vegetation (Oueslati et al., 2013). The effects of climate on soil resources emerge at local or larger scales. Soil resources are affected by topography primarily through the influence of micro-topography on water movement (Oueslati et al., 2013; Yoo et al., 2006.). In addition, soil texture, i.e., the organic, moisture and cation exchange composition, also influences soil resources (Rodríguez et al., 2009b).

Vegetation plays an important role in the regulation of soil resource patterns and availability (Augusto et al., 2002; Gross et al., 1995; Okin et al., 2008). Plants alter the physical, chemical, and biological properties of soil beneath the canopy (Gallardo et al., 2000; Jackson and Caldwell, 1993; Rodríguez et al., 2009a). Many papers have reported that in arid and semi-arid regions, plants enhance soil resource variability by generating and containing soil moisture and nutrients within vegetation patches (Yavitt et al., 2009). In addition, this capability of plants may also affect seedling establishment (Diekmann et al., 2007; Huante et al., 1995; Lawrence, 2003). Simultaneously, the altered spatial pattern of soil resources may in turn influence the functioning and performance of individual plants and microorganisms and, ultimately, ecosystemlevel processes and community structure (Li et al., 2010; Schlesinger et al., 1996). There is a clear bidirectional spatial relationship between plants and soil (Covelo et al., 2008; Ettema and Wardle, 2002; Rodríguez et al., 2009b; Zhou et al., 2008).

Despite a substantial research concerning the heterogeneous nature of soil resources caused by vegetation, there are poorly understood issues in this area of research. First, many studies have been 
performed comparing soil patterns in different environments. Few studies have compared the spatial pattern of soil resources in different secondary succession stages (Diekmann et al., 2007). Second, although studies of heterogeneous soil resource patterns caused by vegetation are fairly common, only trees and shrubs have typically been considered. Few studies have provided high-resolution analyses of soil resources pattern caused by herbaceous plants. Third, research scales are often related to the scale of trees or shrubs (one meter or larger). A further research is necessary to investigate the formation of the spatial pattern of soil resources at a scale more relevant to herbaceous plants (no greater than one meter). Finally, many studies have compared the scales of soil resources and vegetation patches to understand the relationship between the pattern of soil resources and vegetation patches and to identify whether the soil resource patterns were affected by vegetation. These studies have assumed that similar scales share a strong relationship. Though this method is easy to understand, it is not accurate, and some details governing the relationship between soil resources and vegetation are not easy to determine.

In this paper, we have studied four areas with abandonment times of $4,12,22$, and 50 years. The purpose of this paper was to study the dynamic effect of vegetated patches on soil resources patterns at a scale related to herbaceous plants. The objectives of this study were to (i) investigate the pattern of soil resources by geo-statistics analysis of different abandoned areas; (ii) use a point pattern analysis to research the relationship between soil resources patterns and vegetation after different periods of abandonment; (iii) compare these two works to reveal the relationship between soil resources and vegetation and the formation of resource islands. After that, a universal method was devised to investigate this relationship.

\section{Materials and methods}

\subsection{Study area}

This study was performed in the Yangjuangou catchment $\left(36^{\circ} 42^{\prime} \mathrm{N}\right.$, $109^{\circ} 31^{\prime} \mathrm{E}$ ) in the Loess Plateau, Shaanxi Province, China (Fig. 1). This catchment has a semi-arid continental climate, mean annual precipitation of $531 \mathrm{~mm}$ and mean air temperature of $9.85^{\circ} \mathrm{C}$ from 1952 to 2010, according to data from the meteorological station in Yanan city (Fig. 2). The elevation of the catchment ranges from 1050 to $1298 \mathrm{~m}$ (Liu et al., 2012). Rainfall in the catchment is concentrated between June and September. Soil in the study area was derived from loess parent material. The soil type is Calcaric Regosol which is characterized by a uniform texture. It is an infant soil, without distinct development of genetic horizons and zonal characteristics of profile (Huang, 1987). A soil organic layer (10-30 cm) emerges under vegetation coverage. The color of this layer is gray-brown or dark gray-brown. Parent material is under the organic layer. It is an illuvial horizon with little calcium carbonate (Huang, 1987). The composition of the loess in the Yangjuangou catchment is typically more than $50 \%$ silt $(0.002-0.05 \mathrm{~mm})$ and less than $20 \%$ clay $(<0.002 \mathrm{~mm}$ ), and the porosity of the soil is almost 50\% (Liu et al., 2012). The experimental plots were located in abandoned croplands. Due to the sparse population and a grazing ban, there has been little human impact on vegetation in the secondary succession after these croplands were abandoned. Among the native species, Stipa grandis and Carex korshinskii et al. are largely distributed on the sunny slopes, and, Artemisia sacrorum and Artemisia giraldii et al. often have been found on the shady slopes in the Yangjuangou catchment. In this research, different vegetation communities have been found on different test areas, and they were shown in Table 1.
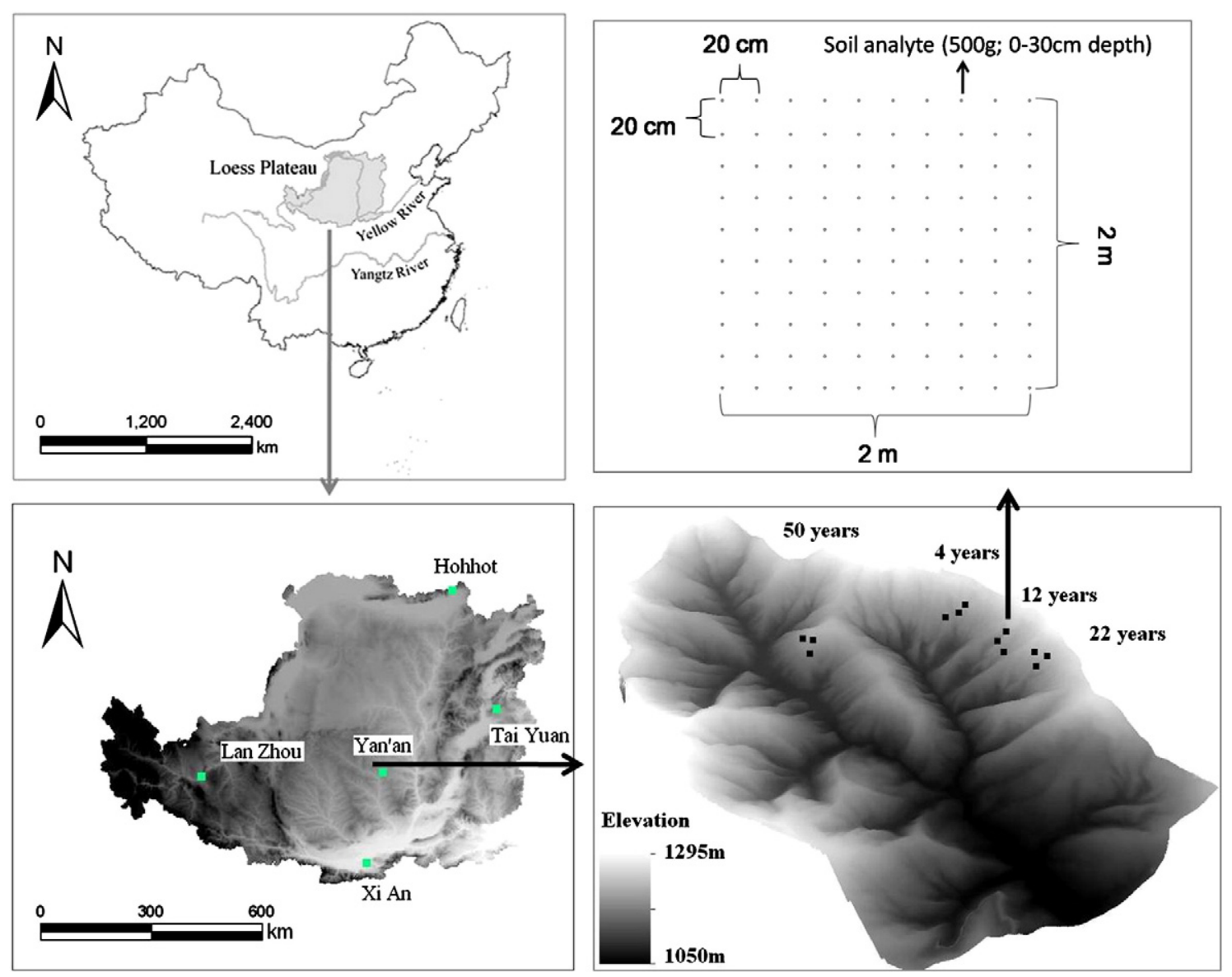

Fig. 1. Locations and design of experimental plots. 


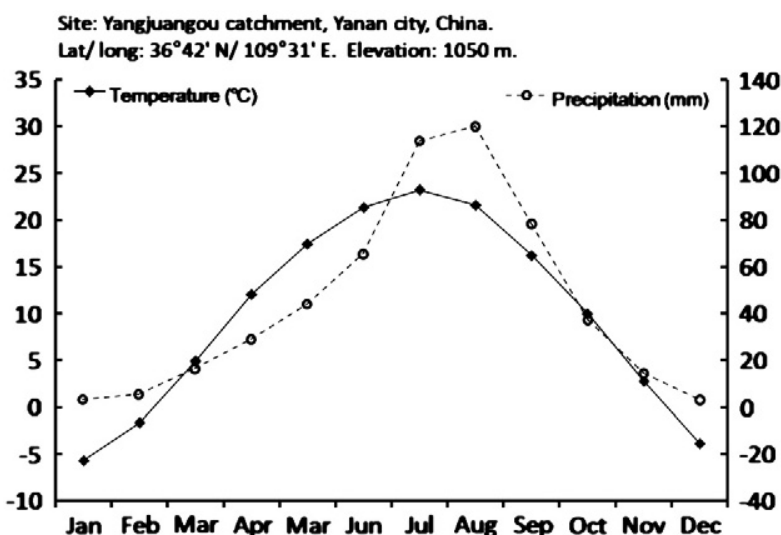

Fig. 2. Walther-Lieth diagram of Yangjuangou catchment, based on the long-term data (1952-2010) of the meteorological station in Yanan city.

\subsection{Experimental design}

For practical reasons, a chronosequence approach was used instead of diachronic studies to study the dynamic effect of vegetation on the pattern of soil resources (Dana and Mota, 2006). Before the experiment, the age of abandonment was determined by personal interviews with landowners and managers within the Yangjuangou catchment. Abandonment is defined as the cessation of plowing and sowing. After the interviews, four abandoned areas were selected with abandonment periods of $4,12,22$ and 50 years. The environment and terrain conditions of these four abandoned farms were all very similar (Table 1) and there has not been any change in the used plowing techniques during the last 50 years in this area. From June to September 2012, 3 randomly distributed plots $(2 \times 2 \mathrm{~m})$ were created in each test area. In each plot, the cover value, location and height of plants were investigated. Systematic samplings of 100 soil analytes were collected at regular intervals on a $20 \times 20 \mathrm{~cm}$ grid (Fig. 1). Soil was collected with an auger to a depth of $30 \mathrm{~cm}$ of soil for each sampling point. In order to reduce the effect of rainfall on the soil water content, all the soil samples were collected on August 26, 2012, with 7 days past since the last rainfall.

\subsection{Laboratory analysis}

Ten soil parameters were determined: average soil particle size (PS), bulk density (BD), pH-value, moisture (SM), organic matter (OM), total nitrogen (TN), total phosphorus (TP), total potassium (TK), total sulfur (TS) and available nitrogen (AN). These parameters were selected

Table 1

The environmental parameters on experimental lands.

\begin{tabular}{|c|c|c|c|c|c|}
\hline $\begin{array}{l}\text { Abandoned } \\
\text { time }\end{array}$ & Slope & Aspect & $\begin{array}{l}\text { Slope } \\
\text { position }\end{array}$ & Elevation & Vegetation community ${ }^{*}$ \\
\hline 4 years & $25^{\circ}$ & WS & Midslope & $1180 \mathrm{~m}$ & $\begin{array}{l}\text { Artemisia scoparia }+ \text { Sonchus } \\
\text { brachyotus }\end{array}$ \\
\hline 12 years & $24^{\circ}$ & WS & Midslope & $1171 \mathrm{~m}$ & $\begin{array}{l}\text { Glycyrrhiza uralensis + Carex } \\
\text { korshinskii }\end{array}$ \\
\hline 22 years & $23^{\circ}$ & WS & Midslope & $1164 \mathrm{~m}$ & $\begin{array}{l}\text { Bothriochloa } \\
\text { ischaemum }+ \text { Cleistogenes } \\
\text { squarrosa }\end{array}$ \\
\hline 50 years & $25^{\circ}$ & WS & Midslope & $1161 \mathrm{~m}$ & $\begin{array}{l}\text { Stipa grandis }+ \text { Cleistogenes } \\
\text { squarrosa }\end{array}$ \\
\hline
\end{tabular}

* The nomenclature of vegetation community is dominant-species nomenclature, followed by Chinese Flora. The vegetation community can be defined by two plants which hold the biggest importance value in the vegetation community. because of their importance for plant growth. All soil samples were sieved ( $2 \mathrm{~mm}$ mesh size) after oven-drying at $80^{\circ} \mathrm{C}$ for $48 \mathrm{~h}$ to calculate the SM. The PS was measured using a laser particle sizer (Mastersizer 2000); the BD was measured using a soil auger; the $\mathrm{pH}$ was analyzed using a calomel electrode with a sleeve-type connection; the OM was determined by the potassium dichromate volumetric method; the TN and TS were measured using an element analyzer (Vario EL III); Morgan's extraction solution (10\% sodium acetate in a 3\% acetic acid buffered at pH 4.8) was used to determine the TP and TK; and the AN was measured using the alkaline hydrolysis diffusion method (Bai et al., 2010).

\subsection{Data analysis}

\subsubsection{Data analysis tools}

Vegetation data and some common statistical analyses were conducted using Microsoft Excel 2007. Box-Cox transformations were performed using R 2.15.2 with the package MASS. Semivariograms were calculated for each variable using R 2.15 .2 with the package gstat. Ripley's K-function and Monte Carlo simulation were performed with $\mathrm{R}$ 2.15.2 and the package ads. The features and names of species were determined according to the Chinese flora from Chinese Vegetation (Wu, 1980).

\subsubsection{Vegetation data analysis}

Plant species were grouped into four vegetation groups according to the following families: Compositae, Leguminosae, Gramineous and Rare species. These vegetation groups were selected because of the hypothesis that the plants in different families have a significant impact on the patterns of soil resources within different abandoned areas. The importance value of each group was determined in areas that had been abandoned for different periods. This importance value of each group is a sum of importance values for all of the species in a group in a particular area. The importance value of one species $=$ (relative cover + relative height)/200. The relative cover was equal to 100 multiplied by the cover of the species divided by the cover of all species in the community. The relative height was calculated in the same way. The greater the importance value is for a particular species, the greater is the impact for this species in the community. Every plant species was described according to the Chinese flora described in Chinese Vegetation (Wu, 1980).

\subsubsection{Exploratory statistical analysis}

To provide a first-hand description of all soil parameters, statistical estimators such as the mean, median, maximum, minimum and coefficient of variation $(\mathrm{CV})$ were calculated. The $\mathrm{CV}$ is the intrinsic heterogeneity induced by the soil environment and cultivation history (Peigné et al., 2009). According to Yavitt et al. (2009), CV values from 0 to 15\% indicate low variability, CV values from 16 to $35 \%$ indicate moderate variability, and $\mathrm{CV}$ values $>36 \%$ indicate high variability (Yavitt et al., 2009).

\subsubsection{Geostatistical analysis}

Prior to analysis, each soil parameter from each area was transformed to a normalized pattern using a Box-Cox transformation (Box and Cox, 1964):

$y=\left\{\begin{array}{c}\frac{x^{\lambda}-1}{\lambda} \lambda \neq 0 \\ \ln x \lambda=0\end{array}\right.$

where $y$ is the transformed variable, $x$ is the variable at the original scale and $\lambda$ is the estimated parameter based on the assumption that the transformed values are normally distributed (Fu et al., 2010).

Geostatistical analyses were used to analyze the spatial dependence of each soil parameter in each area. After Box-Cox transformation, a semivariogram was calculated for each variable. The semivariogram 
was defined as the average dissimilarity of data as a function of distance (Goovaerts, 1999) and can be illustrated as follows:

$\gamma(h)=\frac{1}{2 N(h)} \sum_{i} \sum_{i+h}[z(i)-z(i+h)]^{2}$

where $\gamma$ is the semivariance for each soil parameter data pair separated by a distance lag $h . z$ is defined as the variable under consideration at positions $i$ and $i+h$. For each soil parameter data point, the semivariogram was calculated. The semivariogram shows the average variance in comparisons of soil samples that were sampled at increasing distances. For data with a random distribution, the semivariance trend is nearly flat with increasing distance (Rossi et al., 1992). However, for data with a spatial pattern, the semivariogram first rises in comparison to autocorrelated neighboring sand sample then levels off at the sill that indicates the distance or range $\left(A_{0}\right)$. Samples are spatially independent beyond this distance. A variance exists at a finer scale than the field sampling. This variance is found at a zero lag distance and is called the nugget variance $\left(C_{0}\right)$. A high or low ratio of the structural variance $(C)$ to the sill variance $\left(C+C_{0}\right)$ is used to describe a strong or weak spatial pattern among the data. Additionally, anisotropy was not considered in these calculations, and one meter, which is the half of the maximum sampling distance in each plot, was chosen as the active lag distance in constructing all semivariograms. Either spherical or linear models were selected to fit the soil parameter semivariograms for the ease of comparison and goodness of fit. A spherical model was found to be a good fit for soil parameter semivariograms (Schlesinger et al., 1996). A linear model shows a spatial autocorrelation in the data set. However, the autocorrelation range is greater than one meter (the maximum lag distance). If neither of these two models fit the semivariogram of a soil parameter, the soil parameter was considered to be a random distribution (Diekmann et al., 2007) (Fig. 3).

\subsubsection{Point pattern analysis}

Prior to analysis, 20 soil samples with maximum values were selected for the SM, OM, TN, TP, TK, TS and AN within each plot. Twenty soil samples with minimum values were selected for the BD within each plot. By this method, the plot positions that had high values for SM, OM, TN, TP, TK, TS and AN or low values for BD were located within each plot. This selection was based on the hypothesis that high values for SM, OM, TN, TP, TK, TS and AN or low values for BD play a more important role in the growth of vegetation than do low values for SM, OM, $\mathrm{TN}, \mathrm{TP}, \mathrm{TK}, \mathrm{TS}$ and AN or high values for BD. This location information is important for the determination of the spatial relationship between soil parameters and each vegetation group within each plot.

To determine the spatial relationship between each vegetation group and each soil parameter in different areas, a Ripley's K-function

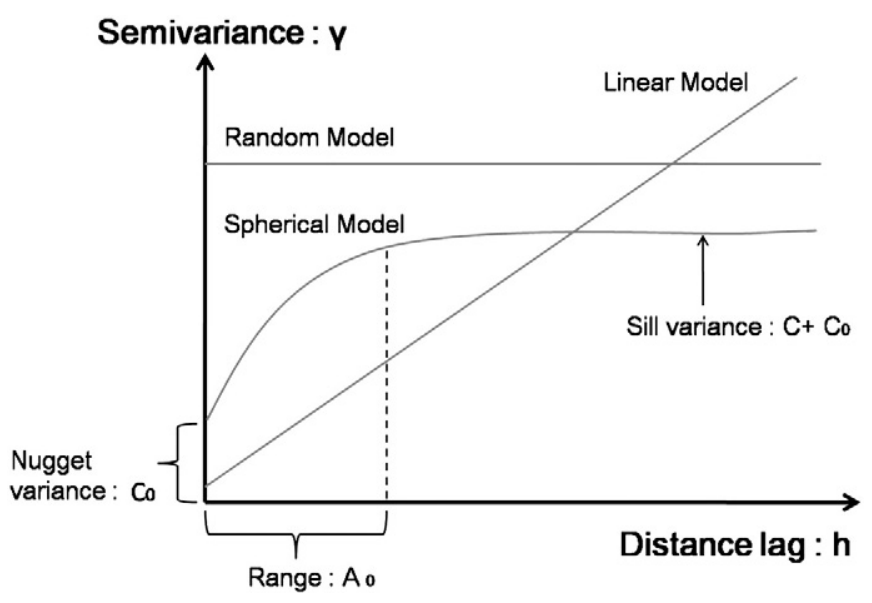

Fig. 3. Theoretical interpretations of semi-variograms.
(Ripley, 1978) was used for a multivariate point pattern analysis as follows:

$\hat{\mathrm{K}}_{12}(t)=\frac{\mathrm{A}}{\mathrm{n}_{1} \mathrm{n}_{2}} \sum_{i=1}^{\mathrm{n}_{1}} \sum_{j=1}^{\mathrm{n}_{2}} \frac{1}{\mathrm{~W}_{i j}} \mathrm{I}_{t}\left(\mathrm{u}_{i j}\right)$

where $t$ is the observation scale; $A$ is the plot area; $n_{1}$ and $n_{2}$ are the sample numbers of a soil parameter and the number of plants within a group in a plot; $i$ and $j$ represent the plant and soil parameters, respectively; $\mathrm{u}_{i j}$ is the distance between the location of a plant within a group and a soil parameter that has been selected within that plot; when $\mathrm{u}_{i j}>t, \mathrm{I}_{t}$ $\left(\mathrm{u}_{i j}\right)=0$; when $\mathrm{u}_{i j} \leq t, \mathrm{I}_{t}\left(\mathrm{u}_{i j}\right)=1 ; \mathrm{W}_{i j}$ is the ratio of a circular area divided by $A$, and the center of that circle is the location of a plant or soil sample that has been selected. The radius of the circle is $\mathrm{u}_{i j}$. Often, this equation can be transformed into a more simple version for better spatial determination and ease of expression (Jansen et al., 2008).

$\hat{\mathrm{L}}(t)=\sqrt{\frac{\hat{\mathrm{K}}_{12}(t)}{\pi}}-t$

$\hat{\mathrm{L}}(t)=0$ indicates complete spatial randomness and there is no spatial relationship between the location of a plant within a group and the soil parameter that has been selected within the plot at scale t. When $\hat{\mathrm{L}}$ $(t)>0$, there is a positive relationship and an accumulation pattern between the location of a plant within a group and the soil parameter that has been selected within the plot at the scale $t$. When $\hat{\mathrm{L}}(t)<0$, there is a negative relationship and a uniform pattern trend between the two variables. In this equation, scale $t$ can be understood as the diameter of the circle. For example, when there is a positive spatial relationship between particular soil parameters and plants within scale $t$, there is an accumulation pattern between the plants and soil parameter within the circle with diameter $t$. In cases of complete spatial randomness, a Monte Carlo simulation was used to assess whether the spatial pattern was significantly different from random using a 99\% confidence level (Herrero-Jáuregui et al., 2012) (Fig. 4).

\section{Results}

\subsection{Vegetation conditions on the different abandoned farms}

Based on the importance value for every species, the importance values of these four groups (Compositae, Leguminosae, gramineous and rare plants) within each abandoned land were calculated (Fig. 5). The importance value of Compositae plants decreased from 0.874 on

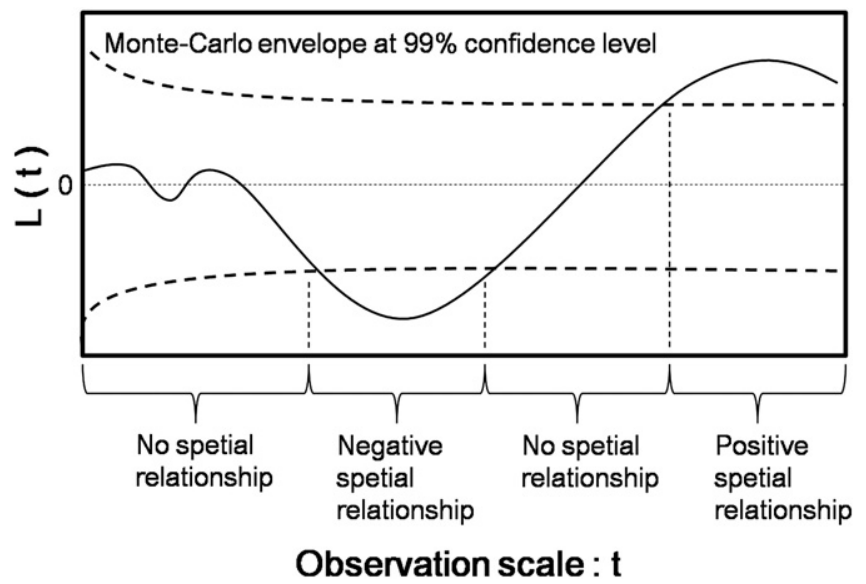

Fig. 4. Theoretical interpretations of point pattern analysis on spatial relationship between vegetation and soil parameters by $\hat{\mathrm{L}}(\mathrm{t})$, a transformation of Ripley's K-function. 


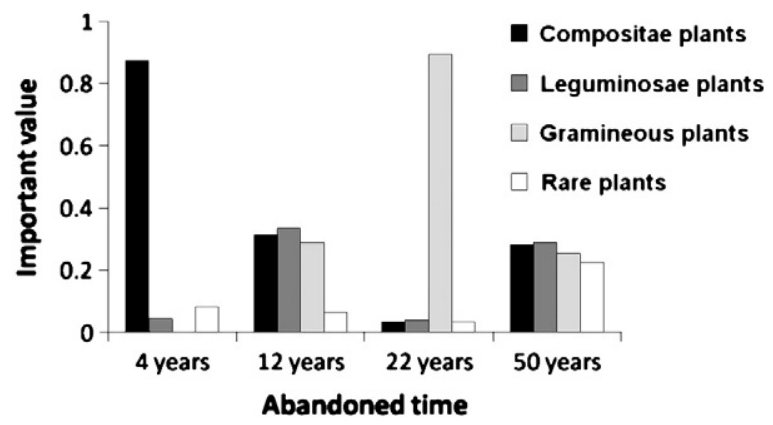

Fig. 5. The important values of four vegetation groups on different abandoned lands.

the 4-year abandoned land to 0.0345 on the 22 -year abandoned land and then slightly increased to 0.282 on the 50-year abandoned land. On every abandoned land, Artemisia species were the primary Compositae plants. Over 70\% of the importance values for Compositae plants were contributed by Artemisia species on every abandoned land (Table 2). The importance value of Compositae plants was significantly higher than that of the other groups at the 4-year time point. This result indicates that Artemisia species were dominant within the

Table 2

Important value of species on different abandoned lands.

\begin{tabular}{|c|c|c|c|c|c|}
\hline Vegetation group & Species & 4 years & 12 years & 22 years & 50 years \\
\hline \multirow[t]{10}{*}{ Compositae plants } & Artemisia capillaris & 0.053 & & & \\
\hline & Sonchus oleraceus & 0.237 & & & \\
\hline & Cirsium setosum & 0.004 & 0.019 & & \\
\hline & Heteropappus altaicus & 0.026 & 0.052 & 0.005 & 0.016 \\
\hline & Artemisia scoparia & 0.471 & 0.013 & 0.026 & 0.003 \\
\hline & Artemisia giraldii & 0.020 & 0.099 & & 0.019 \\
\hline & Artemisia sacrorum & 0.063 & 0.129 & & 0.233 \\
\hline & $\begin{array}{l}\text { Ixeridium } \\
\text { sonchifolium }\end{array}$ & 0.001 & 0.0003 & & 0.003 \\
\hline & Taraxacum mongolicum & & 0.0005 & & \\
\hline & Serratula centauroides & & & 0.003 & 0.009 \\
\hline \multirow{10}{*}{$\begin{array}{l}\text { Leguminosae } \\
\text { plants }\end{array}$} & Sophora davidii & 0.037 & & & \\
\hline & Lespedeza davurica & 0.007 & & & \\
\hline & Glycyrrhiza uralensis & & 0.162 & & \\
\hline & Lespedeza davurica & & 0.110 & 0.031 & 0.130 \\
\hline & Oxytropis hirta & & 0.006 & 0.007 & 0.015 \\
\hline & Oxytropis bicolor & & 0.043 & & 0.003 \\
\hline & Lespedeza floribunda & & 0.014 & & 0.050 \\
\hline & Melilotus alba & & & & 0.054 \\
\hline & Vicia cracca & & & & 0.008 \\
\hline & Lespedeza cuneata & & & & 0.028 \\
\hline \multirow{6}{*}{ Gramineae plants } & Bothriochloa ischaemun & & 0.003 & 0.504 & \\
\hline & Carex korshinskii & & 0.219 & 0.069 & 0.004 \\
\hline & Cleistogenes squarrosa & & 0.067 & 0.210 & 0.036 \\
\hline & Helictotrichon schellian & $u m$ & & 0.094 & 0.024 \\
\hline & Cleistogenes polyphylla & & & 0.018 & 0.004 \\
\hline & Stipa grandis & & & & 0.186 \\
\hline \multirow[t]{16}{*}{ Rare plants } & Geranium pratense & 0.008 & & & \\
\hline & Periploca sepium & 0.046 & & & \\
\hline & Incarvillea sinensis & 0.025 & & & \\
\hline & Viola philippica & 0.0004 & 0.047 & 0.011 & 0.006 \\
\hline & Euphorbia humifusa & 0.0003 & & 0.0003 & 0.0002 \\
\hline & Patrinia scabiosaefolia & 0.001 & & & 0.027 \\
\hline & Clematis fruticosa & & 0.003 & & \\
\hline & Bupleurum chinense & & 0.003 & 0.013 & 0.003 \\
\hline & Euphorbia esula & & 0.0004 & & 0.007 \\
\hline & Potentilla tanacetifolia & & 0.009 & 0.002 & 0.024 \\
\hline & Polygala tenuifolia & & & 0.005 & 0.046 \\
\hline & Silene gallica & & & & 0.080 \\
\hline & Ostryopsis davidiana & & & & 0.015 \\
\hline & Viola dissecta & & & & 0.001 \\
\hline & Patrinia heterophylla & & & & 0.009 \\
\hline & Siphonostegia chinensis & & & & 0.006 \\
\hline
\end{tabular}

plant community at the 4-year time point. The trend of importance values for Leguminosae plants was not obvious from the 4- to 50-year time points. However, this group occupied the primary position within the plant community at the 12-year time point. Gramineous plants were not found at the 4-year time point, but this species increased in frequency from 0 to 0.894 on land abandoned for 22 years, and returned to 0.254 at the 50-year time point. This group which mainly consisted of bunch grass occupied the main position on land abandoned for 22 years. In addition, the rare plant family presented the lowest importance values on all test plots. However, on land abandoned for 50 years, the important values of all these four groups were approximately equal. Some species in the rare plants group were endemic species in this research. For example, Geranium pratense, Periploca sepium and Incarvillea sinensis were endemic on land abandoned for 4 years, and Silene gallica, Ostryopsis davidiana, Viola dissecta, Patrinia heterophylla and Siphonostegia chinensis were endemic on land abandoned for 50 years (Table 2).

\subsection{Soil parameters on the different abandoned farms}

The variability of soil parameters in each abandoned land was evaluated by its CV (Yavitt et al., 2009) (Table 3). In this study, the pH was the least variable soil parameter. The $\mathrm{CV}$ of the $\mathrm{pH}$ was no more than 1.5 in each of the four lands. Similar to the $\mathrm{pH}$, the TK also had a low CV (0-15\%) on all these land. All of the remaining soil parameters had moderate variability (CV: 16-35\%) on land that had been abandoned for 4 years. Thus, the CVs for the various soil parameters at the 4-year time point were mostly similar. On land abandoned for 12 years, most soil parameter CVs were low, with the exception of two high values for the AN and OM and one moderate value for the TS. Generally, the $\mathrm{CV}$ s from most of these parameters were relatively low and thus had similar levels on this land. On land abandoned for 22 years, all of the parameters had moderate variability except for the TK, $\mathrm{pH}$ and SM, which had low values. On land abandoned for 50 years, there were 4 low CVs (TK, pH, SM and PS), 5 moderate CVs (TN, TP, TS, AN and BD), and a high $\mathrm{CV}(\mathrm{OM})$. Thus there were clear differences in all of the soil parameters on land abandoned for 50 years (Table 3).

In this study, the patch size of soil resources was investigated at a scale relevant for herbaceous plants on three of the test plots on each abandoned land (Table 4). The autocorrelation range in geo-statistical data indicates the size of soil resources patches (Yavitt et al., 2009). An autocorrelation range $\left(\mathrm{A}_{0}\right)$ can be calculated from one plot, and a range of $A_{0}$ can be determined from three plots on each abandoned land. After geo-statistical analysis, the TN and AN produced a similar patch size at the 12-year time point because they both generated a similar autocorrelation range $(70-75 \mathrm{~cm})$ calculated from their spherical model semivariograms. A linear model was selected to fit the TN and AN semivariograms on land abandoned for 22 and 50 years. However, on land abandoned for 4 years, the TN range was from 42 to $45 \mathrm{~cm}$, which is different from the random distribution of the AN. The OM, SM and BD had a similar patch size on land abandoned for 4 (range: 29-36 cm) and 12 (range: 60-70 cm) years. However, on land abandoned for 22 years, the patch size of the OM was from 64 to $66 \mathrm{~cm}$. A linear model was selected to fit the semivariograms of the SM and BD, which means that the range of the SM and $\mathrm{BD}$ was greater than one meter. A linear model was also selected on land abandoned for 50 years to fit the semivariograms for these three soil parameters. We showed that the patch sizes, which share a close relationship with herbaceous plants, for the TN, AN, OM, SM and BD likely increased with an abandonment period of 4 to 50 years. For the TP and TS, a random distribution was found in the parameter patterns. Thus, patches did not exist in the pattern of the TP and TS in the different plots within one meter. The TK had a range from 49 to $50 \mathrm{~cm}$ on land abandoned for 50 years. It appears that the TK only established patches at this time point (Table 4). 
Table 3

Statistics estimators to describe all soil parameters. ${ }^{\mathrm{a}, \mathrm{b}}$

\begin{tabular}{|c|c|c|c|c|c|c|c|c|c|c|c|}
\hline Abandoned land & & $\mathrm{TN} / \%$ & $\mathrm{TP} / \%$ & TK/\% & $\mathrm{TS} / \%$ & $\mathrm{AN} / \mathrm{mg} / \mathrm{kg}$ & $\mathrm{OM} / \%$ & $\mathrm{pH}$ & $\mathrm{BD} / \mathrm{g} / \mathrm{ml}$ & $\mathrm{SM} / \%$ & PS/um \\
\hline \multirow[t]{5}{*}{4 years } & Mean & 0.038 & 0.042 & 1.558 & 0.015 & 34.494 & 9.244 & 8.550 & 1.056 & 12.666 & 48.796 \\
\hline & Median & 0.037 & 0.046 & 1.554 & 0.014 & 32.448 & 9.175 & 8.550 & 1.116 & 12.452 & 45.471 \\
\hline & Maximum & 0.061 & 0.057 & 1.751 & 0.029 & 75.083 & 14.026 & 8.750 & 1.296 & 28.005 & 77.545 \\
\hline & Minimum & 0.025 & 0.003 & 1.394 & 0.007 & 18.488 & 6.561 & 8.280 & 0.370 & 10.053 & 38.329 \\
\hline & $\mathrm{CV} / \%$ & 16.249 & 29.555 & 5.057 & 27.130 & 31.191 & 17.173 & 1.206 & 16.971 & 16.509 & 20.890 \\
\hline \multirow[t]{5}{*}{12 years } & Mean & 0.075 & 0.057 & 1.659 & 0.015 & 51.992 & 11.061 & 8.267 & 1.185 & 10.675 & 52.425 \\
\hline & Median & 0.074 & 0.058 & 1.623 & 0.015 & 46.219 & 9.691 & 8.230 & 1.218 & 10.638 & 51.875 \\
\hline & Maximum & 0.111 & 0.067 & 1.974 & 0.022 & 145.638 & 29.199 & 8.490 & 1.412 & 12.495 & 69.186 \\
\hline & Minimum & 0.052 & 0.013 & 1.459 & 0.004 & 29.807 & 5.745 & 8.110 & 0.833 & 9.577 & 41.883 \\
\hline & $\mathrm{CV} / \%$ & 14.437 & 13.132 & 6.922 & 21.808 & 36.218 & 36.549 & 1.196 & 10.998 & 5.112 & 12.480 \\
\hline \multirow[t]{5}{*}{22 years } & Mean & 0.053 & 0.051 & 1.596 & 0.015 & 36.623 & 5.840 & 8.238 & 1.065 & 12.161 & 48.575 \\
\hline & Median & 0.051 & 0.058 & 1.569 & 0.014 & 34.523 & 5.922 & 8.240 & 1.088 & 12.155 & 46.417 \\
\hline & Maximum & 0.102 & 0.066 & 1.982 & 0.036 & 85.647 & 12.825 & 8.390 & 1.357 & 14.328 & 76.784 \\
\hline & Minimum & 0.041 & 0.004 & 1.279 & 0.008 & 16.224 & 2.374 & 7.440 & 0.361 & 11.000 & 34.515 \\
\hline & $\mathrm{CV} / \%$ & 16.147 & 31.397 & 9.883 & 33.864 & 30.684 & 34.564 & 1.458 & 16.575 & 4.202 & 19.755 \\
\hline \multirow[t]{5}{*}{50 years } & Mean & 0.059 & 0.051 & 1.421 & 0.015 & 29.020 & 7.367 & 8.233 & 1.176 & 11.074 & 53.086 \\
\hline & Median & 0.055 & 0.056 & 1.384 & 0.014 & 27.166 & 6.757 & 8.240 & 1.227 & 11.109 & 52.496 \\
\hline & Maximum & 0.189 & 0.066 & 1.880 & 0.026 & 61.877 & 21.138 & 8.400 & 1.412 & 13.169 & 77.335 \\
\hline & Minimum & 0.043 & 0.005 & 1.181 & 0.009 & 13.206 & 2.525 & 7.980 & 0.079 & 7.732 & 42.445 \\
\hline & $\mathrm{CV} / \%$ & 33.226 & 26.798 & 11.343 & 20.553 & 34.318 & 36.681 & 0.814 & 18.726 & 6.163 & 13.345 \\
\hline
\end{tabular}

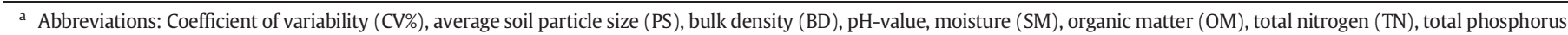
(TP), total potassium (TK), total sulfur (TS) and available nitrogen (AN).

b Three hundred soil samples were collected on each abandoned land to determine these listed soil parameters.

\subsection{The relationship between vegetation patterns and soil parameters}

There were four primary parts for the multivariate point pattern analysis of the positions of selected soil parameters and plants within a group (Table 5). First, 5 positive relationships among the spatial pattern of Compositae plants and soil parameters were tested on land abandoned for 4 years. Following a test with a 99\% confidence level, an accumulation pattern relationship between the locations of Compositae plants and the distribution of TN, AN, OM or BD were tested at a scale of 10 to $18 \mathrm{~cm}$. Additionally, there was also an aggregation pattern relationship between Compositae plants and the TK within 50 to $56 \mathrm{~cm}$. Second, on land abandoned for 12 years, there was an aggregate pattern relationship between leguminous plants and the OM within 66 to $74 \mathrm{~cm}, 4$ aggregation pattern relationships between leguminous plants and the TN, TP, AN or SM within a scale of 75 to $86 \mathrm{~cm}$, and an accumulation pattern relationship between leguminous plants and the TS within 85 to $99 \mathrm{~cm}$. Third, on land abandoned for 22 years, there were only two aggregation pattern relationships: gramineous plants and the OM within 81 to $85 \mathrm{~cm}$, and gramineous plants and the TP within 85 to $87 \mathrm{~cm}$. Fourth, on land abandoned for 50 years, 3 aggregation patterns were tested: gramineous plants and the TP within 67 to $82 \mathrm{~cm}$, gramineous plants and the TK within 21 to $64 \mathrm{~cm}$, and gramineous plants and the TS within 51 to $60 \mathrm{~cm}$ (Table 5).

Table 4

Geo-statistics analysis on semivariogram of soil parameters on different abandoned lands. ${ }^{\mathrm{a}, \mathrm{b}}$

\begin{tabular}{lllll}
\hline & 4 years & 12 years & 22 years & 50 years \\
\hline TN & $42-45 \mathrm{~cm}$ & $70-72 \mathrm{~cm}$ & Linear & Linear \\
AN & Random & $71-75 \mathrm{~cm}$ & Linear & Linear \\
TK & Random & Random & Random & $49-50 \mathrm{~cm}$ \\
OM & $29-30 \mathrm{~cm}$ & $60-61 \mathrm{~cm}$ & $64-66 \mathrm{~cm}$ & Linear \\
SM & $29-32 \mathrm{~cm}$ & $59-62 \mathrm{~cm}$ & Linear & Linear \\
BD & $32-36 \mathrm{~cm}$ & $65-70 \mathrm{~cm}$ & Linear & Linear \\
TP & Random & Random & Random & Random \\
TS & Random & Random & Random & Random \\
\hline
\end{tabular}

${ }^{a}$ Abbreviations: Average soil bulk density (BD), moisture (SM), organic matter (OM), total nitrogen (TN), total phosphorus (TP), total potassium (TK), total sulfur (TS) and available nitrogen (AN).

b Random: There is a random distribution about the soil parameter. Linear: there is a linear model about the soil parameter. The data range: the range of autocorrelation range $\left(A_{0}\right)$ of the soil parameter calculated after fit its semivariograms by Spherical model.

\section{Discussion}

\subsection{The effect of vegetation on the patch patterns of soil resources}

We have determined in this study that more soil parameters accumulated around the dominant vegetation families in the community than accumulated around other vegetation families (Table 5). The dominant vegetation families were Compositae on land abandoned for 4 years, Leguminosae on land abandoned for 12 years, and gramineous plants on land abandoned for 22 and 50 years (Fig. 5). Correspondingly, several interesting observations were made regarding the relationships between vegetation and soil resource patterns. First, most soil resources were aggregated around plants from the Compositae family on land abandoned for 4 years. Soil resources then shifted to plants from the Leguminosae family on land abandoned for 12 years and gramineous plants on land abandoned for 22 and 50 years (Table 5). This indicates that the Compositae family played a greater role in the formation of soil resource patches than did the other families at the 4-year time point. Similarly, the Leguminosae family played a greater role in the formation of soil resource patches than the other families on land abandoned for 12 years, and gramineous plants dominated soil resource patches on land abandoned for 22 and 50 years.

These observations suggest that the dominant plant species in community at a particular succession stage play a primary role in the formation of resource islands. Resource islands continuously develop throughout vegetation succession. Because Artemisia species are drought and barren resistant and developed fibrous root systems, they often take root on abandoned land in the early stages of succession as pioneer species. As the dominant species on land abandoned for 4 years, Artemisia species have an early influence on the soil resource patterns. They increase the soil porosity through the growth of their roots and aggregate nutrients like OM and soil N through litter decomposition and the effects of microorganisms. These effects create the environmental conditions needed for the formation of resource islands. After plants from the Leguminosae family become the dominant species in the plant community, they accumulate more nutrients in the soil (TN, AN, TP, TS, OM and SM) than other plants because of their ability to fix nitrogen (Table 5). Therefore, more plants will grow near them than will grow farther away. This may be the primary stage in which resource islands are established. When gramineous plants, also known as bunch grasses, become the dominate species in the plant community, their 
Table 5

Point pattern analysis between the positions of selected soil parameters and vegetation groups. ${ }^{\mathrm{a}, \mathrm{b}}$

\begin{tabular}{|c|c|c|c|}
\hline & Compositae plants & Leguminous plants & Gramineous plants \\
\hline 4 years & $\begin{array}{l}\text { TN: } 10-17 \mathrm{~cm} \text { AN: } 10-18 \mathrm{~cm} \\
\text { TK: } 50-56 \mathrm{~cm} \text { SOM: } 10-16 \mathrm{~cm} \\
\text { BD: } 11-16 \mathrm{~cm}\end{array}$ & & \\
\hline 12 years & & $\begin{array}{l}\text { TN: } 75-85 \mathrm{~cm} \text { AN: } 75-85 \mathrm{~cm} \\
\text { TP: } 79-80 \mathrm{~cm} \text { TS: } 85-99 \mathrm{~cm} \\
\text { SOM: } 66-74 \mathrm{~cm} \text { SM: } 83-86 \mathrm{~cm}\end{array}$ & \\
\hline $\begin{array}{l}22 \text { years } \\
50 \text { years }\end{array}$ & & & $\begin{array}{l}\text { TP: } 85-87 \mathrm{~cm} \text { SOM: } 81-85 \mathrm{~cm} \\
\text { TP: } 67-82 \mathrm{~cm} \text { TK: } 21-64 \mathrm{~cm} \\
\text { TS: } 51-60 \mathrm{~cm}\end{array}$ \\
\hline
\end{tabular}

a Abbreviations: Average soil bulk density (BD), moisture (SM), organic matter (OM), total nitrogen (TN), total phosphorus (TP), total potassium (TK), total sulfur (TS) and available nitrogen (AN).

$\mathrm{b}$ The data range: The aggregation scale between soil parameters and vegetation groups.

highly developed fibrous root system captures more soil resources than do those of other families either from surrounding areas via runoff or directly from the soil. These features create ameliorated microclimatic conditions that are beneficial for seedling establishment. Thus, resource islands led by gramineous plants are established in this succession stage. However, on land abandoned for 22 years in this study, gramineous plants did not aggregate SM and other necessary nutrients important for vegetative growth (Table 5). It may be that gramineous plants are the dominant species in transitional communities earlier than 22 years following abandonment. Thus, after gramineous plants became the dominant species, species abundance increased within these new resource islands. On land abandoned for 22 years, other plants, in addition to gramineous plants within resource islands, have an effect on soil resource patterns. Thus, although there is a positive spatial relationship between gramineous plants and the OM and TP, other soil parameters may also aggregate in these resource islands. As is the case with resource islands on land abandoned for 22 years, there is a developed resource island on land abandoned for 50 years. Thus, though there is a positive spatial relationship between gramineous plants and some nutrients (TP, TK and TS), other soil parameters may aggregate around these resource islands.

There are other studies similar to this one concerning the effect of vegetation on soil resource patterns. For example, in a work on the spatial pattern of nitrogen, Gross et al. (1995) found that the patch size of soil nutrients reflected the cover, composition or size of the plants within the community (Gross et al., 1995). In a research performed by Okin et al. (2008), vegetation was corroborated to determine the spatial heterogeneity of soil resources. Proximity between the range of a soil nutrient and a type of vegetation (shrub or tree) suggests that a particular type of vegetation is responsible for the spatial pattern of that soil nutrient. In their study, the patch sizes and pattern of macronutrients and OM appeared to be impacted by both trees and shrubs (Okin et al., 2008). Gallardo (2003) found that the patch size and pattern of $\mathrm{N}$ and OM coincided with the tree canopy, and the semivariogram range of these two soil parameters coincided with the canopy diameter. Thus, trees have a significant effect on soil N and OM. However, the concentration of available $\mathrm{P}$ in the soil is more spatially linked to the root density than is the $\mathrm{N}$ concentration. As the tree canopy diameter is often smaller than the root diameter, the fact that soil $\mathrm{N}$ and $\mathrm{OM}$ have a smaller patch size than available P can be explained (Gallardo, 2003). Robertson et al. (1993) compared an abandoned site with a cultivated site. They found that the plowing effect on soil patch resources may persist for decades after the land is abandoned (Robertson et al., 1993). By comparing the semivariogram range of the OM with plant size, Gallardo and Paramá (2007) suggested that resource patch sizes may be influenced by past vegetation because the current vegetation community at the study site was successional (Gallardo and Paramá, 2007).

There is a difference between this study and a previous paper. When evaluating the relationship between vegetation and soil resource patterns, a direct comparison between the sizes of the canopy and the soil resource patches has been used in these works. In this paper, in contrast, analysis of a point pattern was used to characterize this relationship. We would like to suggest that point pattern analysis is a more effective method in identifying spatial relationships between variables.

\subsection{Development processes of soil resource patches}

On land abandoned for 4 years, high values of TN and OM and a low value of BD defined a soil resource patch after testing by geo-statistical analysis (Table 4). We found that these three parameters accumulated around Compositae plants (Table 5). This result demonstrates that there are soil resource patches of TN, OM and BD around plants from the family Compositae. Therefore, Compositae species may be the primary factor that determines the location of soil resource patches containing elevated levels of $\mathrm{TN}, \mathrm{OM}$ and $\mathrm{BD}$. These results also demonstrate that the patch sizes of TN, OM and BD are larger than the scale they aggregated around plants. This can be explained as a soil resource patch of TN, OM or BD contains several individual plants. Plants from the Compositae family, with Artemisia being the primary species, are often pioneer species. On land with a short period of abandonment, they are typically the dominant species. In these communities, plant roots may enhance soil porosity and litter decomposition, thereby increasing nutrient cycling beneath the plants. Thus, the high values of $\mathrm{TN}$ and $\mathrm{OM}$ and the low value of BD establish a soil resource patch. In addition, individual Artemisia species often grow together because of asexual reproduction, giving the appearance of several individual plants within a single soil resource patch of TN, OM and BD.

We observed that high levels of AN and TK can be deposited around plants from the Compositae family and yet not form soil resource patches. Indeed, soil resource patches formed with high SM values are not found around Compositae plants. This phenomenon can be explained if AN and TK have strong spatial variability around plants. So, their patch patterns may exist at a smaller scale than one meter. The phenomenon can be explained if the abandonment time is not long enough, SM may be affected more by farmland micro-topography than by the colonizing Compositae species. So, though there may be an SM soil patch, transitional vegetation plays little role in its formation.

On land abandoned for 12 years, the high values of TN, AN, OM and SM established a soil resource patch (Table 4). These four parameters accumulated around Leguminosae species (Table 5). Thus, plants that form the Leguminosae family may be the primary factor establishing soil resource patches of TN, AN, OM and SM. As the dominant species in a plant community, Leguminosae species accumulate OM in their immediate environment. Nevertheless, this phenomenon is different from plants from the Compositae, which accumulate SM. Twelve years after abandonment, the plants dominating the succession may affect SM more than the micro-topography of the previous farmland. As nitrogen-fixing plants, the Leguminosae can increase TN and AN contents and cycling rates (Koutika et al., 2005; Prescott, 2002). These plants may also play an important role in the patterns of other nutrients, such as TP and TS (Binkley et al., 2000). So this may explain our 
observation that TN, AN, TP and TS aggregate around plants of the Leguminosae family. Nevertheless, TP and TS do not form soil resource patches like TN and AN. Soil nitrogen is mainly cycled through OM, so biological processes may impact its pattern (Hirobe et al., 2003), while the cycling mechanisms of TP and TS are driven by both biological and geochemical processes. Because of strong interactions with soil minerals, TP and TS may form complex patterns (Rodríguez et al., 2009a). Therefore, they do not form soil resource patches. This cycling mechanism of TP and TS may also be used to explain a similar phenomenon in other abandoned areas. In addition, although low values of BD help establish soil resource patches, these low levels do not accumulate around plants. Low BD levels may be caused by past vegetation, Compositae plants in the last successional stage for example, which may have had a substantial effect on the BD (Gallardo and Paramá, 2007). Although plants of the Compositae have been superseded by plants of the Leguminosae, some soil properties, (e.g., the BD) may not change immediately. This phenomenon could also explain the similar situation for BD on land abandoned for 22 and 50 years.

On land abandoned for 22 years, only high values for the $\mathrm{OM}$ established a soil resource patch around gramineous plants. Thus, gramineous plants are the primary factor establishing the soil resource patches for OM. Because a linear model was a good fit to the semivariograms for TN, AN, SM and BD (Table 4), these soil parameters may have patch sizes larger than one meter. These four soil parameters did have a not have a positive relationship with plants in our point pattern analysis (Table 4). We suggest that resource islands can reach maturity in this succession stage. Therefore, these four soil parameters may be more affected by resource islands containing many plant species than by one component within the islands.

On land abandoned for 50 years, resource islands are mature. In this stage, only high values of the TK develop as soil resource patches and accumulate around gramineous plants. In contrast, TK does not accumulate in soil resource patches in lands abandoned for 4, 12 and 22 years (Table 4). Potassium is an important macronutrient, and its transport primarily depends on diffusion (Mäser et al., 2002). The aggregation of TK requires efficient uptake from the soil by plant roots (Gierth and Maser, 2007). Thus, the formation of TK patches may be largely dependent on the development of vegetation patches. TK will not accumulate in soil resource patches until vegetation patches reach maturity. In addition, the CV of TK increases with longer periods since abandonment. This phenomenon may also be explained by the development of resource islands, which leads to a two-phase mosaic of vegetated and bare areas (Okin et al., 2008). OM and SM form soil resource patches, but they do not aggregate around plants from one family. We suggest that all the plant species within a resource island can contribute to the formation of soil resource patches.

\subsection{The feedback relationship between vegetation and soil resources}

The feedback between vegetation and soil resources has been studied by many researchers, in addition to this study. The spatial pattern of soil resources is affected by vegetation, litter decomposition, stem flow, and throughfall (Døckersmith et al., 1999). Vegetation influences soil resources by root litter decomposition, root exudates release, and root turnover (Diekmann et al., 2007; Reed et al., 2005). In contrast, soil resource patterns can influence belowground biomass, vegetation patch size, and competition within plant populations and between different species (Wijesinghe et al., 2005). It has been suggested that the spatial pattern of soil resources has a significant effect on plant communities (Diekmann et al., 2007) and vice versa. Thus, it is not easy to discuss what is cause and what is consequence about vegetation and soil resource pattern development. This is a feedback system, and there is a collaborative development between them.

In this study, much work was performed to evaluate this feedback relationship. However, other factors may also interact with the spatial pattern of soil resources. For example, microbial biomass and moss that have spatial dependence within one meter (Saetre and Baath, 2000) may also have an effect on the pattern of soil resources.

In addition, some limits exist in this study. For practical reasons, only four abandoned farms were studied. As a result, key succession stages (the succession of Leguminosae to gramineous plants as the dominant species in the community) during the abandoned period between 12 and 22 years were not available in this study. Thus, the state of soil resource formation was not documented during these transitions. In addition, because of limits on the study scale, we were not able to study the resource patches larger than one meter. However, our results suggest that many soil resource patches are larger than one meter after 22 years of abandonment. This work requires a follow up in the future.

\subsection{The integration of geostatistics, point pattern analysis and spatial comparison}

Geostatistics and point pattern analysis are often used separately in research on the effect of vegetation on soil resources patterns. Due to the different focuses of these methods, this often leads to bias in the research results. In this study, Geostatistical analysis was used to test the patch sizes and spatial patterns of various soil parameters, and point pattern analysis was used to address the accumulation scale and spatial relationship between plants and soil resources. Then, spatial comparisons were made to analyze the difference between the patch sizes and resource accumulation. With this method, the soil spatial pattern and relationship between vegetation and soil resources were well described. These techniques were integrated into a method called the Integration of Geostatistics, Point pattern analysis and Spatial comparison for research on the effect of vegetation on soil resource patterns at a fine scale (Fig. 6).

It is an important method to reveal the formation of resource islands and to identify their ecological function at a fine scale. With this method, some useful information has been provided to land managers about the scale of soil nutrient patterns in the study area. This information is useful for managers to clearly understand ground conditions and effectively manage land. And, this information is also useful for researchers to avoid the spatial autocorrelation of soil elements when performing

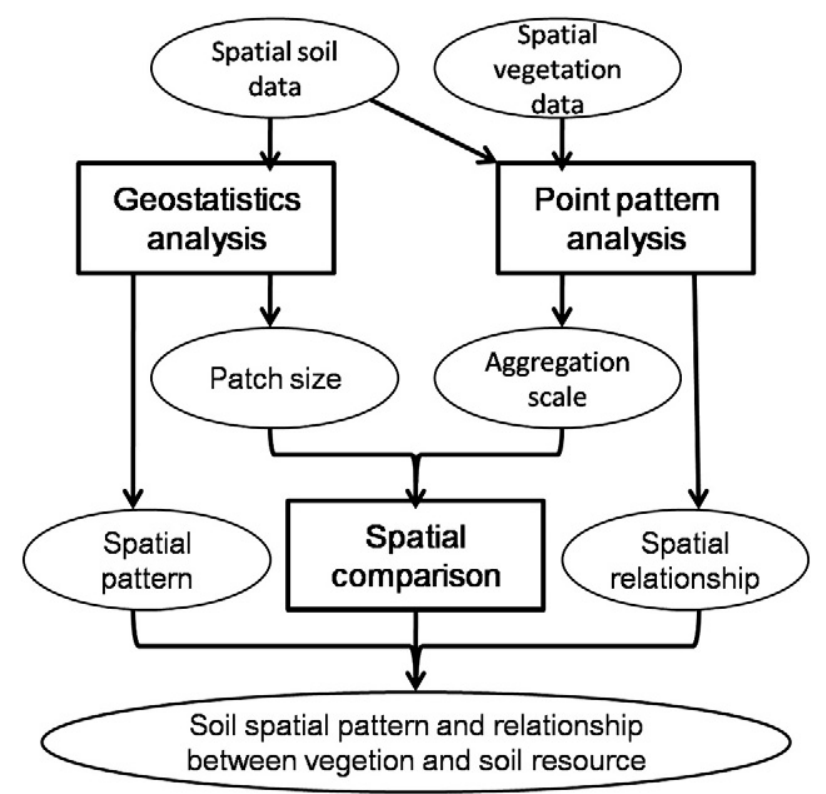

Fig. 6. Flow chart Integration of Geostatistics, Point pattern analysis and Spatial comparison. Geostatistics analysis is used to test the patch sizes and spatial patterns of soil parameters, and point pattern analysis is used to deal with the aggregation scale and spatial relationship between plants and soil resources. Spatial comparison is to analysis the difference between the patches size and aggregation. By this method, soil spatial pattern and relationship between vegetation and soil resource can be well understood. 
field experiments. Though the methods (Integration of Geostatistics, Point pattern analysis and Spatial comparison) are established in Loess Plateau of China and may have some regional limitations, it can be a reference for other studies worldwide.

\section{Conclusion}

In this study we have evaluated the effect of vegetation on soil resource patterns from four different abandoned farms, and several mechanisms behind the relationship between vegetation and soil resource patterns were identified. We determined that the dominant vegetation families on land abandoned from 4 to 50 years were the Compositae, Leguminosae, and gramineous plants. Correspondingly, on land abandoned for 4 to 50 years, most soil resources accumulated around Compositae, Leguminosae, and gramineous plants. Therefore, the dominant family of plants during a particular succession stage will play a primary role in the formation of resource islands in that stage. Over the course of vegetative succession, resource islands will develop and mature.

With the development of resource islands, the patterns of soil resources change. On land abandoned for 4 years, high levels of TN and $\mathrm{OM}$ and low levels of $\mathrm{BD}$ establish a soil resource patch, and these three parameters accumulate around Compositae plants. High levels of AN and TK, which accumulate around Compositae plants, do not form soil resource patches. In contrast, high levels of SM, which forms soil resource patches, do not accumulate around Compositae plants. On land abandoned for 12 years, high levels of TN, AN, OM and SM establish soil resource patches, and these four parameters aggregate around Leguminosae plants. The high levels of TP and TS also aggregate around Leguminosae plants, but TP and TS do not form soil resource patches. In addition, though the low levels of BD establish soil resource patches, they do not aggregate around plants. On land abandoned for 22 years, only OM established soil resource patches and high levels of OM accumulate around gramineous plants. TN, AN, SM and BD may have patch sizes of more than one meter, but these four soil parameters do not have positive spatial relationships with plants. The high levels of TP aggregate around gramineous plants, but TP does not form soil resource patches. On land abandoned for 50 years, only high levels of TK establish soil resource patches and accumulate around gramineous plants. In contrast, TK did not establish soil resource patches on land abandoned for 4, 12 and 22 years. TN, AN, OM and SM may form soil resource patches, but they did not accumulate around plants. The high levels of TP and TS aggregate around gramineous plants, but they do not form soil resource patches.

\section{Acknowledgments}

This work was funded by the State Forestry Administration (No. 201004058), the National Natural Science Foundation of China (No. 41230745) and the Chinese Academy of Sciences (No. GJHZ 1215).

\section{References}

Augusto, L., Ranger, J., Binkley, D., Rothe, A., 2002. Impact of several common tree species of European temperate forests on soil fertility. Ann. For. Sci. 59, 233-253.

Bai, J.-H., et al., 2010. Spatial and temporal distribution patterns of nitrogen in marsh soils from an inland alkaline wetland - a case study of Fulaowenpao wetland, China. Acta Ecol. Sin. 30 (4), 210-215.

Binkley, D., Giardina, C., Bashkin, M.A., 2000. Soil phosphorus pools and supply under the influence of Eucalyptus saligna and nitrogen-fixing Albizia falcataria. For. Ecol. Manag. 128 (3), 241-247.

Box, G.E.P., Cox, D.R., 1964. An analysis of transformations. J. R. Stat. Soc. Ser. A 26, 211-243.

Covelo, F., Rodriguez, A., Gallardo, A., 2008. Spatial pattern and scale of leaf N and P resorption efficiency and proficiency in a Quercus robur population. Plant Soil 311 (1-2), 109-119.

Døckersmith, I.C., Giardina, C.P., Sanford, R.L., 1999. Persistence of tree related patterns in soil nutrients following slash-and-burn disturbance in the tropics. Plant Soil 209 (1) 137-157.
Dana, E.D., Mota, J.F., 2006. Vegetation and soil recovery on gypsum outcrops in semi-arid Spain. J. Arid Environ. 65 (3), 444-459.

Diekmann, L.O., Lawrence, D., Okin, G.S., 2007. Changes in the spatial variation of soil properties following shifting cultivation in a Mexican tropical dry forest. Biogeochemistry 84 (1), 99-113.

Ettema, C.H., Wardle, D.A., 2002. Spatial soil ecology. Trends Ecol. Evol. 17, 177-183.

Fu, W., Tunney, H., Zhang, C., 2010. Spatial variation of soil nutrients in a dairy farm and its implications for site-specific fertilizer application. Soil Tillage Res. 106 (2), 185-193.

Gallardo, A., 2003. Effect of tree canopy on the spatial distribution of soil nutrients in a Mediterranean Dehesa. Pedobiologia 47 (2), 117-125.

Gallardo, A., Paramá, R., 2007. Spatial variability of soil elements in two plant communities of NW Spain. Geoderma 139 (1-2), 199-208.

Gallardo, A., Rodríguez-Saucedo, J.J., Covelo, F., Fernández, A.R., 2000. Soil nitrogen heterogeneity in a Dehesa ecosystem. Plant Soil 222, 71-82.

Gierth, M., Maser, P., 2007. Potassium transporters in plants-involvement in K + acquisition, redistribution and homeostasis. FEBS Lett. 581 (12), 2348-2356.

Goovaerts, P., 1999. Geostatistics in soil science: state-of-the-art and perspectives. Geoderma 89, 1-45.

Gross, K.L., Pregitzer, K.S., Burton, A.J., 1995. Spatial variation in nitrogen availability in three successional plant communities. J. Ecol. 83, 357-367.

Guo, D., Mou, P., Jones, R.H., Mitchel, R.J., 2002. Temporal changes in spatial patterns of soil moisture following disturbance: an experimental approach. J. Ecol. 90, 338-347.

Herrero-Jáuregui, C., Sist, P., Casado, M.A., 2012. Population structure of two low-density neotropical tree species under different management systems. For. Ecol. Manag. 280, 31-39.

Hirobe, M., Koba, K., Tokuchi, N., 2003. Dynamics of the internal soil nitrogen cycles under moder and mull forest floor types on a slope in a Cryptomeria japonica D. Don plantation. Ecol. Res. 18 (1), 53-64.

Huang, Z.L., 1987. Discussion of classification of yellow cultivated loessial soils in Shaanxi. Acta Pedol. Sin. 24, 266-271

Huante, P., Rincon, E., Chapin, F.S., 1995. Responses to phosphorus of contrasting successional tree-seedling species from the tropical forest of Mexico. Funct. Ecol. 9, 760-766.

Jackson, R.B., Caldwell, M.M., 1993. Geostatistical patterns of soil heterogeneity around individual perennial plants. J. Ecol. 81, 683-692.

Jansen, P.A., Bongers, F., van der Meer, P.J., 2008. Is farther seed dispersal better? Spatial patterns of offspring mortality in three rainforest tree species with different dispersal abilities. Ecography 31 (1), 43-52.

Koutika, L.S., et al., 2005. Leguminous fallows improve soil quality in south-central Cameroon as evidenced by the particulate organic matter status. Geoderma 125 (3-4), 343-354.

Lawrence, D., 2003. The response of tropical tree seedlings to nutrient supply: metaanalysis for understanding a changing tropical landscape. J. Trop. Ecol. 19, 1-12.

Li, J., Richter, D.d, Mendoza, A., Heine, P., 2010. Effects of land-use history on soil spatial heterogeneity of macro- and trace elements in the Southern Piedmont USA. Geoderma 1-2, 60-73.

Liu, Y., Fu, B., Lü, Y., Wang, Z., Gao, G., 2012. Hydrological responses and soil erosion potential of abandoned cropland in the Loess Plateau, China. Geomorphology 138 (1), 404-414.

Mäser, P., Gierth, M., Schroeder, J.I., 2002. Molecular mechanisms of potassium and sodium uptake in plants. Plant Soil 247, 43-54.

Okin, G.S., et al., 2008. Spatial patterns of soil nutrients in two southern African savannas. J. Geophys. Res. 113 (G2).

Oueslati, I., Allamano, P., Bonifacio, E., Claps, P., 2013. Vegetation and topographic control on spatial variability of soil organic carbon. Pedosphere 23 (1), 48-58.

Peigné, J., Vian, J.-F., Cannavacciuolo, M., Bottollier, B., Chaussod, R., 2009. Soil sampling based on field spatial variability of soil microbial indicators. Eur. J. Soil Biol. 45 (5-6), 488-495

Prescott, C.E., 2002. The influence of the forest canopy on nutrient cycling. Tree Physiol. 22 (15-16), 1193-1200.

Puigdefabregas, J., 2005. The role of vegetation patterns in structuring runoff and sediment fluxes in drylands. Earth Surf. Process. Landf. 30 (2), 133-147.

Reed, H.E., Seastedt, T.R., Blair, J.M., 2005. Ecological consequences of C-4 grass invasion of a C-4 grassland: a dilemma for management. Ecol. Appl. 15 (5), 1560-1569.

Reynolds, J.F., Virginia, R.A., Kemp, P.R., Soyza, A.G., Tremmel, D.C., 1999. Impact of drought on desert shrubs: effects of seasonality and degree of resource island development. Ecol. Soc. Am. 69 (1), 69-106.

Ripley, B.D., 1978. Spectral avalysis and the analysis of pattern in plant communities. J. Ecol. 66, 965-981.

Robertson, G.P., Crum, J.R., Ellis, B.G., 1993. The spatial variability of soil resources following long-term disturbance. Oecologia 451-456.

Robertson, G.P., et al., 1997. Soil resources, microbial activity and primary production across an agricultural ecosystem. Ecol. Appl. 7, 158-170.

Rodríguez, A., Durán, J., Fernández-Palacios, J.M., Gallardo, A., 2009a. Spatial pattern and scale of soil $\mathrm{N}$ and $\mathrm{P}$ fractions under the influence of a leguminous shrub in a Pinus canariensis forest. Geoderma 151 (3-4), 303-310.

Rodríguez, A., Durán, J., Fernández-Palacios, J.M., Gallardo, A., 2009b. Spatial variability of soil properties under Pinus canariensis canopy in two contrasting soil textures. Plant Soil 322 (1-2), 139-150.

Rossi, R.E., Mulla, D.J., Journel, A.G., Franz, E.H., 1992. Geostatistical tools for modeling and interpreting ecological spatial dependence. Ecol. Monogr. 62, 277-314.

Saetre, P., Baath, E., 2000. Spatial variation and patterns of soil microbial community structure in a mixed spruce \pm birch stand. Soil Biol. Biochem. 32, 909-917.

Sauer, T.J., Cambardella, C.A., Meek, D.W., 2006. Spatial variation of soil properties relating to vegetation changes. Plant Soil 280 (1-2), 1-5. 
Schlesinger, W.H., Raikes, J.A., Hartley, A.E., Cross, A.F., 1996. On the spatial pattern of soil nutrients in desert ecosystems. Ecology 77 (2), 364-374.

Segoli, M., Ungar, E.D., Shachak, M., 2008. Shrubs enhance resilience of a semi-arid ecosystem by engineering and regrowth. Ecohydrology 1 (4), 330-339.

Wijesinghe, D.K., John, E.A., Hutchings, M.J., 2005. Does pattern of soil resource heterogeneity determine plant community structure? An experimental investigation. J. Ecol. 93 (1), 99-112.

Wu, Z.Y., 1980. China Vegetation. Science Press, Beijing.
Yavitt, J.B., et al., 2009. Spatial heterogeneity of soil chemical properties in a lowland tropical moist forest, Panama. Aust. J. Soil Res. 47, 674-687.

Yoo, K., Amudson, R., Heimsath, A.M., Dietrich, D.E., 2006. Spatial patterns of soil organic carbon on hillslopes: integrating geomorphic processes and the biological $\mathrm{C}$ cycle. Geoderma 130, 47-65.

Zhou, Z.Y., et al., 2008. Variation in small-scale spatial heterogeneity of soil properties and vegetation with different land use in semiarid grassland ecosystem. Plant Soil 310 (1-2), 103-112. 